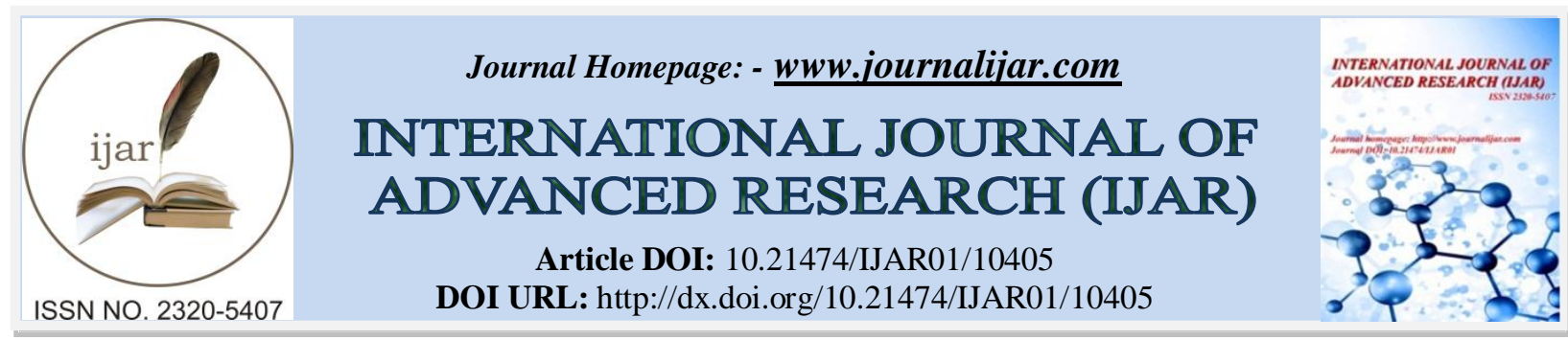

RESEARCH ARTICLE

\title{
THE METHODOLOGY OF ORGANIZING AND CONDUCTING LABORATORY WORKS IN PRACTICAL PROFESSIONAL EDUCATION
}

\author{
Shavkat Kosimov ${ }^{1}$, Pulatov G'afur Ergashovich ${ }^{2}$ and Toshpolatov Boybo'ri Boymurodovich ${ }^{3}$ \\ 1. Termez Branch of TSPU Named After Nizami, PhD Professor, Republic of Uzbekistan. \\ 2. Termiz Branch of Tashkent State Technological University Named After I.Karimov, Republic of Uzbekistan \\ 3. Termiz State University, Republic of Uzbekistan.
}

\section{Manuscript Info}

\section{Manuscript History}

Received: 30 November 2019

Final Accepted: 31 December 2019

Published: January 2020

Key words:-

Laboratory, Theoretical Training,

Practical Work, Method, Research

Work, Independent Work, Experience,

Function

\section{Abstract}

This article discusses how to organize and conduct lab work. Laboratory training is one of the independent types of integration of students' theoretical knowledge, skills and abilities in a holistic process of teaching and research.

\section{Introduction:-}

Termiz branch of Tashkent state Technological University named after I.Karimov, Republic of Uzbekistan Termiz state University, Republic of Uzbekistan

Lab work is considered as one of the forms of practical training as a form and method of teaching in didactics. The terms "laboratory" and "laboratorial" are derived from the Latin language "lab" - labor, work, difficulty; Laboro means to work, to try, to get anxious, to overcome difficulties. Laboratory work is training in the use of mental and physical efforts to find previously unknown ways and means to solve scientific and daily life issues.

Lab work is a form of training designed to build the necessary professional skills. During the lab sessions, students work under the guidance of a teacher or independently to deepen their theoretical knowledge and develop the skills of independent experimentation. Laboratory training is one of the types of independent practice and research activities of students in general secondary education, vocational training and higher education institutions to deepen their theoretical knowledge and develop skills of independent experimentation [3].

Laboratory work is one of the kinds of independent work that integrates students' theoretical knowledge, skills and abilities in a holistic process of teaching and research.

The terms "laboratory work" and "laboratory practice" are exactly the same if the laboratory work is conducted throughout the course. Lab work can also be included in other complex forms of training. In this case, lab work is seen as a method of teaching.

During one of the laboratory activities as one of the types of student learning activities, students perform one or more laboratory work under the leadership of teacher, consistent with the content of the study subject. 


\section{Main part}

What is the essence of lab work as a teaching method? Lab work is a method of teaching in which students are supervised by a teacher

According to the plan they perform specific tasks and in the course of their implementation they gain a new understanding of the subject matter, consolidate the learned subject, apply theoretical knowledge to solve practical problems and develop skills for solving certain situations.

As S.I. Arkhangelsky stated the main task of the laboratory practice is to establish the relationship between theory and practice on the basis of experimental studies in specially equipped rooms [2].

Laboratory work is aimed at deep study of the basics of teaching science, acquiring modern methods and skills of experimentation with the use of the latest teaching techniques [4].

The tasks facing the laboratory practice include a broadening of the students' worldview, increasing their interest in the subject, and the implementation of complex creative research activities.

Many modern explorers believe that it is necessary to develop a process of activating not only practical skills but also the creative abilities of students through the use of laboratory practice.

The purpose of the laboratory classes is to master the scientific and theoretical principles of the subject being studied by students, to master the latest experimental techniques in the relevant science sector, to instrument the acquired knowledge, and then to apply the research and practice issues. The solution to problems, in other words, it is considered to establish a connection between theory and practice. The laboratory classes will stimulate the student's work on the subjects being studied. It is often stated that the most intensive and rhythmic work of students during the semester is done on academic disciplines that the functions of laboratory include:

1. Learning function (accelerates the development of learning topics);

2. Developmental function (development of imagination, memory, spatial thinking, creativity, focus);

3. Educational function (influencing various aspects of character - organizational, responsibility, independence, etc.);

4. Motivational-stimulating function (creates conditions for engaging students in active research and transformation of educational information that enhance cognitive activity);

5. Reflexive function (allows students to understand themselves compared to others; develop their ability to control and analyze their actions, to identify and correct their own mistakes, to evaluate and correct the results of their actions);

6. Diagnostic function (allows the teacher to determine the specifics of student development, their level of knowledge and skills acquisition).

\section{Discussion:-}

The leading didactic goal of laboratory work is to experimentally validate and test certain theoretical rules (regularities, dependencies). The leading didactic goal of the lab is to develop practical skills - professional (ability to perform certain activities, skills to perform operations) and learning (ability to handle the learning tasks needed in subsequent learning activities). In most cases, both of these didactic goals are closely intertwined, and for some training sessions, the term "the practical -laboratorial training " is utilized .

Methods of laboratory works. Laboratory work is carried out on more complicated sections of the training program. They are given important role in establishing links between theoretical and practical training (production training), independent study and analysis of various laws, interrelations in the pedagogical process, systematization of conclusions based on the work done. An analysis of the literature on the organization of laboratory practice shows that different methods of their implementation have been developed so far. Researchers, unlike traditional laboratory methods, seek to eliminate formalism in the implementation of laboratory practice, to develop educational technologies that help them gain greater understanding of the theoretical subject and develop students' creative potential. List of laboratory and practical works, hours allocated for their implementation in the working program of the course.

The composition of lab assignments should be calculated in such a way that the majority of students will be required to complete the time spent in the lab. 
In addition to the independent work of students, the necessary structural elements of the laboratory work are given directions, as well as analysis and evaluation of the work done, and the assessment of students' planned mastery. Before performing laboratory tests, students should check their knowledge and theoretical training and in laboratory work with specially equipped teaching facilities - compliance with occupational safety, fire and electrical safety instructions during laboratory work with students:

\section{The overall structure of laboratory work includes:}

1. Introduction part: Arrangement of lessons (check the students' attendance and readiness for work); general instruction (explain the subject of laboratory work, its goals and objectives; discuss preparation of students for the assignment; brief overview of the theoretical knowledge required for the work;

2. Self-study work of students (the ways of performing the laboratory tasks, the main algorithms for their performance on a concrete sample are considered; the task is performed;

3. Conclusion part (the results of the laboratory work are analyzed, errors in the course of the assignment are identified and the reasons for their occurrence are identified, the students reflect their own actions).

\section{Innovation of laboratory lessons is caused by:}

1. Achievement of developmental and learning objectives with the aim of developing students' general and professional competences in the design, development and improvement of teaching aids in the field of network preparation;

2. Selection and implementation of problematic and developing teaching methods as well as principles and methods of teaching techniques;

3. Organization of independent work in preparation for the lesson;

4. Analysis of the level of mastering the methodological skills and implementation of its methodological introspection.

The following types of activities are used during laboratory training:

1. Individual work on performance of laboratory tasks;

2. Working with each other and checking their knowledge in pairs during the tasks;

3. Discussing of methodological problems in collective;

4. Performing laboratory tasks under the supervision of a teacher.

\section{References:-}

1. Avazov IL, Muslimov N, Kosimov Sh., Khodiev U., Avazov E. Methods and technologies of practical vocational training in professional colleges (on drawings, tables and drawings) Methodical manual. Tashkent: NAVRUZ, 2014. - B. 300.

2. Arkhangelsky S.I. Lecture on the theory of evolution in the workplace. -M.: 1974. - p. 200.

3. Khodjabaev AR, Kosimov Sh. Methods of organizing and conducting practical vocational education. Educational-methodical manual. - T .: UMKXTTKMO and UKPGI, 2007. - B. 148

4. Kosimov Sh.U. Scientific and pedagogical bases of the organization of practical professional education in professional colleges Monograph. -Tashkent: Science and Technology, 2014-B. 160. 